OPEN ACCESS

Edited by:

Eugene A. Goodilin,

Lomonosov Moscow State

University, Russia

Reviewed by:

Guanglin Xia,

Fudan University, China

Serguei Savilov,

Lomonosov Moscow State

University, Russia

*Correspondence:

Mika Sillanpää

mikaetapiosillanpaa@duytan.edu.vn

Pavel V. Krivoshapkin

krivoshapkin@scamt-itmo.ru

Specialty section:

This article was submitted to

Nanoscience,

a section of the journal

Frontiers in Chemistry

Received: 02 April 2020

Accepted: 27 May 2020

Published: 30 June 2020

Citation:

Navrotskaya $A G$, Aleksandrova DD, Krivoshapkina EF, Sillanpää $M$ and

Krivoshapkin PV (2020) Hybrid Materials Based on Carbon

Nanotubes and Nanofibers for Environmental Applications.

Front. Chem. 8:546.

doi: $10.3389 /$ fchem.2020.00546

\section{Hybrid Materials Based on Carbon Nanotubes and Nanofibers for Environmental Applications}

\author{
Anastasiya G. Navrotskaya ${ }^{1}$, Darya D. Aleksandrova ${ }^{1}$, Elena F. Krivoshapkina ${ }^{1}$, \\ Mika Sillanpää ${ }^{2,3,4 *}$ and Pavel V. Krivoshapkin ${ }^{1 *}$ \\ ${ }^{1}$ ChemBio Cluster, ITMO University, Saint Petersburg, Russia, ${ }^{2}$ Institute of Research and Development, Duy Tan University, \\ Da Nang, Vietnam, ${ }^{3}$ Faculty of Environment and Chemical Engineering, Duy Tan University, Da Nang, Vietnam, ${ }^{4}$ Faculty of \\ Health, Engineering and Sciences, School of Civil Engineering and Surveying, University of Southern Queensland, \\ Toowoomba, QLD, Australia
}

With the advances in material science, hybrid nanomaterials with unique mechanical, electrical, thermal and optical characteristics have been developed. Among them, hybrids based on filamentous forms of carbon, such as carbon nanotubes and carbon nanofibers, in combination with inorganic nanoparticles attract particular attention. Due to the structure and morphology, charge and energy transfer processes lead to synergistic effects that allow the use of less material with higher productivity. To clarify these issues, this review will summarize and discuss the relevant studies of the use of inorganic compounds of various chemical groups in modifying carbon nanomaterials for ecological applications.

\footnotetext{
Keywords: carbon nanotubes, carbon nanofibers, hybrid nanomaterials, inorganic nanoparticles, environmental application
}

\section{INTRODUCTION}

Carbon based materials have a number of different properties, and today, are used in all areas of life, including industry, metallurgy, medicine, optics, and environmental protection. However, the rapid development of industries demands more advanced materials with new characteristics created for future uses. The solution was found in the creation of hybrid materials that not only combine the properties of individual components, but also lead to synergistic effects.

Briefly, hybrid materials (HMs) are a result of mixing chemically different components with the formation of interactions, such as Van der Waals, hydrogen bonding, weak electrostatic interactions or covalent bonds. When formed, HMs have a structure different from that of their component materials, but inherit some of their properties and functions. The important factor is the inner structure of the hybrid. By manipulating this aspect, we can control the physicochemical properties of the hybrid material. Combination of carbon nanomaterials (CNMs) with polymers and inorganic nanoparticles improves mechanical (Gomathi et al., 2005; Zhao et al., 2011; Dillon et al., 2015; Wu et al., 2017), electrical (Whitsitt and Barron, 2003; Hang et al., 2005; Ivnitski et al., 2008; Liang et al., 2012), thermal (Cui et al., 2011; Chen L. et al., 2014; Aghabozorg et al., 2016; Hameed et al., 2019), sorptive (Deng et al., 2005; Choi et al., 2010; Czech et al., 2015; Saud et al., 2015; Navrotskaya et al., 2019) and catalytic (Wu et al., 2009; Paula et al., 2011; Aazam, 2014; Kim et al., 2014) properties(Kumar et al., 2008; Wu et al., 2009; Cui et al., 2011; Dillon et al., 2015). 


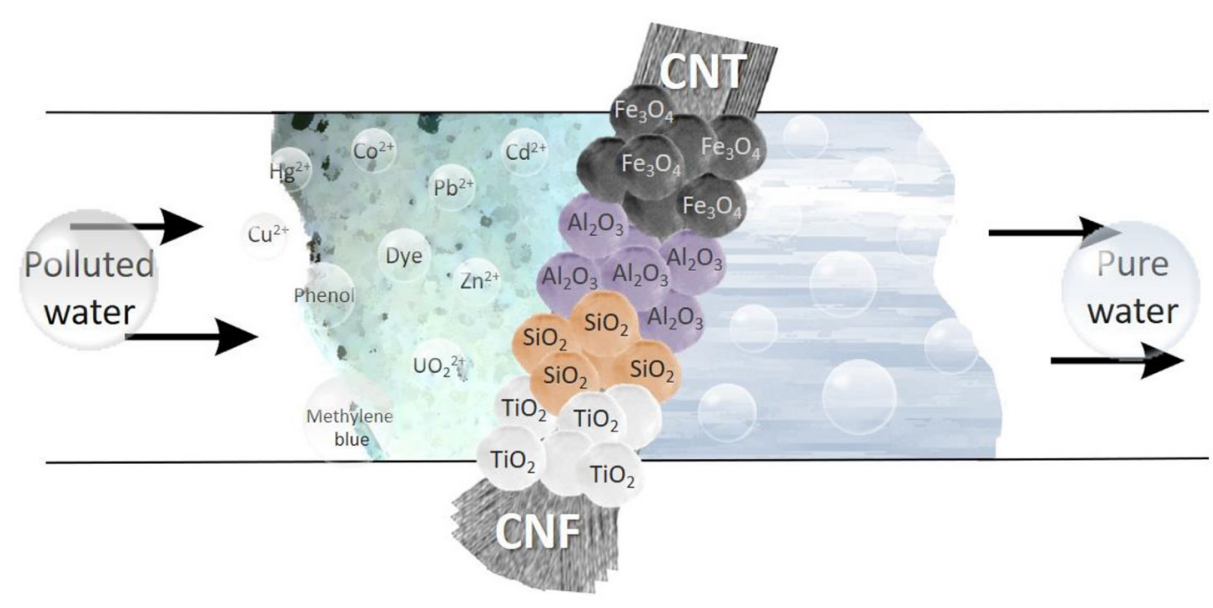

FIGURE 1 | Creation and application of hybrid materials.

Thus, currently there emerges an opportunity to modify CNMs with various nanomaterials using elements of the periodic table, namely metal and metal oxide nanoparticles and inorganic salts. In this context, this review summarizes recent progress in the fabrication and utilization of hybrid materials based on carbon nanomaterials and inorganic nanoparticles. It is especially worth noting that carbon structures, such as graphite, diamond, glassy carbon, graphene, amorphous powders, carbon fibrous materials, carbon nanofibers (CNFs), and carbon nanotubes (CNTs), are very interesting materials for research, development and large-scale production. One of the many advantages of CNTs and CNFs is their length to width ratio $(>1,000)$, which results in a filamentous structure which translates to a high specific surface area (Wu et al., 2009; Paula et al., 2011; Aazam, 2014; Kim et al., 2014). In this regard, this review focuses solely on the advances of hybrid materials based on CNFs and CNTs for environmental applications, which distinguishes it from a number of works dedicated to carbon nanomaterials (Figure 1).

\section{CARBON NANOMATERIALS}

\section{Carbon Nanotubes}

Carbon nanotubes were first reported by Radushkevich and Lukyanovich in 1952 (Thakur and Thakur, 2016) and scientifically reported by Iijima in 1991 (Iijima, 1991). Carbon nanotubes are a seamless cylindrical graphene layer with half of a fullerene molecule at each end (Sarkar et al., 2018; Vashist et al., 2018a,b). CNTs are several nanometers in diameter, but several millimeters in length (Thakur and Thakur, 2016). Depending on the number of layers, CNTs can be single-walled (single-layer) (SWCNTs) or multi-walled (multi-layer) (MWCNTs) (Dai, 2002; Aqel et al., 2012; Das et al., 2014; Postnov et al., 2016). MWNTs are more attractive for widespread use as they are cheaper than SWCNTs (Aqel et al., 2012; Liu et al., 2013; Postnov et al., 2016; Thakur and Thakur, 2016). MWCNTs are made up of several concentric graphene pipes. Individual layers may be described as SWCNTs, which can be a semiconductor or metal. CNTs have a porous structure (Zeng et al., 2014; Chen et al., 2015; Zaytseva and Neumann, 2016).

Carbon nanofibers (CNFs) are filamentous nanomaterials that have mechanical and electrical properties similar to CNTs (Bergmann and Machado, 2015). There are, however, some key differences. Firstly, CNFs are not hollow. Also, the structure of CNFs can be described as graphene layers arranged perpendicularly or at an angle to the fiber axis (Klein et al., 2008; Mishakov et al., 2008; Feng et al., 2014; Yan et al., 2015). The most common CNF structures are "stack of coins" (or planeparallel, "stacked"), "Christmas-tree structure" (or stack of cones, "fishbone," coaxial-conical), and "stack of cups" (or "lampshades," "bamboo") (Klein et al., 2008).

The similar structure of CNFs is due to their growing mechanism, which depends on the geometric characteristics of metal catalyst particles and the carbon source gas (Poveda and Gupta, 2016). CNFs are about several micrometers in length and have diameters ranging from 5 to $200 \mathrm{~nm}$ (Huang et al., 2010; Feng et al., 2014). Ballistic electron transport and tensile strength along the axis, as in diamond, are inherent characteristics of CNTs. CNFs, on the other hand, have higher reactivity and electron transfer through the sidewalls, which is important for functionalization and electrochemical application, respectively (Klein et al., 2008).

\section{Purification and Functionalization of CNTs and CNFs}

One of the stages of hybrid materials preparation is removing amorphous carbon, fullerenes, and metal catalyst particles from the CNFs and CNTs surface (Eder, 2010). There are several purification methods, each with its own advantages and disadvantages. Process efficiency should be the main criterion when choosing a purification method. It depends on the purity of the starting material, time and temperature of oxidation, $\mathrm{pH}$ and oxidizing agent. For example, carbon impurities can be removed via oxygen treatment, which is simply passing an $\mathrm{H}_{2} \mathrm{~S}$ and $\mathrm{O}_{2}$ air mixture over the CNFs and CNTs. However, oxidation often results in broken surface tubes or fibers, especially when 
combined with ultrasonic and high-temperature processing. Oxidation via strong acids, such as $\mathrm{HNO}_{3}, \mathrm{H}_{2} \mathrm{SO}_{4}$, another purification method, leads to broken surface tubes or fibers, as well as the formation of various functional groups. For the removal of metal catalyst particles without interfering with the carbon nanostructure, non-oxidizing acid treatment (for example $\mathrm{HCl}$ ) is usually used. This leads to the fact that the metal nanoparticles move into the solution and leave the nanosystem. As an alternative to the above methods, hightemperature annealing in vacuum or inert gas can be performed. The processing temperature depends on the purpose and ranges from 600 to $2,000^{\circ} \mathrm{C}$.

Much research has been dedicated to the surface functionalization of nanotubes for the creation of new materials with unique properties. This implies that CNTs are treated with different substances to form different functional groups on the surface (Thakur and Thakur, 2016). Covalent functionalization occurs when a covalent bond is formed between the carbon surface and the modifying agent. Functional groups can form at the end or on a sidewall of the nanotubes and nanofibers. For a single-walled carbon nanotube, this type of functionalization can lead to a shift in the electronic structure and thereby affect the conductivity. In the case of multi-walled carbon nanotubes, the internal electronic structure is preserved and new surface characteristics appear, which expands the possibilities of their application (Thakur and Thakur, 2016). In fact, covalent functionalization is carried out by organic molecules that interact with carboxyl groups after surface oxidation (Bright, 2000; Sahoo et al., 2010; Gao et al., 2012; Rabti et al., 2016).

Another type of functionalization-namely non-covalent functionalization-arises through Van der Waals forces and hydrogen bonding (Eder, 2010). Unlike covalent functionalization, it one does not lead to numerous surface defects or to any changes in the mechanical and conductive properties. In this case, modifying agents are various active substances and polymers that increase the solubility of CNTs in hydrophilic solvents and their dispersion in a polymer or ceramic matrix. Aromatic compounds (porphyrins, pyrenes) can also be included here due to $\pi-\pi$-interaction with the delocalized electron cloud of CNTs. The high curvature of CNTs determines reactivity connecting with $\pi$-orbital mismatch. The nanotube end, the fullerene hemispheres, are more reactive than the sidewalls. These properties can be used for the selective functionalization of CNTs.

Articles (Bright, 2000; Sahoo et al., 2010; Gao et al., 2012; Rabti et al., 2016) pay special attention to the positive influence of CNT surface modification. Through this process, the metal catalyst particles enter the solution in the form of salt and leave the nanosystem (Rao et al., 2007). In addition, the surface modification of carbon nanomaterials can lead to the formation of hydroxyl, carbonyl and carboxyl groups (Yang et al., 2009; Zawisza et al., 2012), and is most effectively achieved when the nanotubes (as sorbent) are oxidized using $\mathrm{NaOCl}, \mathrm{HNO}_{3}$ and $\mathrm{KMnO}_{4}$ (Rao et al., 2007; Ihsanullah et al., 2016).

Carbon nanofibers can also be subjected to surface functionalization, but (unlike CNTs) their entire surface can be modified. CNFs activation by nitric acid or electrochemical oxidation can be used to form oxygen-containing groups without degradation of CNFs structure (Huang et al., 2010).

\section{SYNTHESIS OF HYBRID MATERIALS}

Inorganic hybrids based on CNTs and CNFs can be synthesized via ex situ and in situ methods. The first of these involves the separate preparation of the inorganic component in the desired size and morphology (usually spherical nanoparticles), then the attachment of this component to the carbon surface through covalent, non-covalent or electrostatic interactions. On the contrary, the in situ method involves the synthesis of an inorganic component in the presence of initial or functionalized CNTs and CNFs, on which the component grows in the form of particles, nanowires, or thin films (Eder, 2010). Filling the inside of a CNT with inorganic compounds from the gas or liquid phase is carried out by capillary forces based on condensation or wetting.

The valuable advantages of hybrid materials are the variety of synthesis routes and their relative simplicity. These materials can be obtained at low temperatures, through sol-gel and hydrothermal reactions, as well as in various morphologies, for example, in the form of three-dimensional structures, thin films or nanoparticles. The choice of methods for the synthesis of inorganic hybrids based on CNTs and CNFs and the degree of their synergistic effect depend on the type and purity of carbon materials, as well as their surface functionalization.

\section{Sol-Gel Method}

Sol-gel method is nowadays a common practice and can be said to be a comparatively new type of synthesis. This synthesis method results in the uniformed distribution of inorganic particles on the surface of the carbon nanomaterials. This process is diffusioncontrolled, and the changing $\mathrm{pH}$ causes precursors to polymerize and form the inorganic particles. Different types of inorganic coatings can be created depending on the precursors used. For example, the hydrolysis of titanium isopropoxide resulted in a titanium dioxide matrix (Kim et al., 2011; Li et al., 2011; Hamid et al., 2014; Ge et al., 2015); iron (III) nitrate-iron (III) oxide matrix (Sun et al., 2005, 2018; Hassan et al., 2013; Wan et al., 2015); and also probably the creation of $\mathrm{ZrO}_{2}, \mathrm{HfO}_{2}$, and $\mathrm{Ta}_{2} \mathrm{O}_{5}$ oxide gels (Miller and Ko, 1996; Benad et al., 2018; Kiselev et al., 2019). Fixing elemental oxide on CNTs or CNFs surfaces changes hybrid materials characteristics.

\section{Hydrothermal Treatment}

Hydrothermal (and solvothermal) synthesis is conducted with a special piece of equipment called an autoclave under fixed pressure and temperature. Reagents are loaded into the autoclave then left in the oven for a period of time, allowing the reaction to take place without direct supervision (Byrappa and Adschiri, 2007; Yoshimura and Byrappa, 2008; Baruah and Dutta, 2009). During hydrothermal synthesis, aqueous solvents or mineralizers work under temperature and pressure to dissolve and recrystallize usual insoluble materials and decompose or recycle any waste material (Byrappa and Yoshimura, 2013). This process is carried out at high temperatures. As the precursors 
are the same as with the sol-gel synthesis method, hydrolysis is possible (Pirajno, 2009; Byrappa and Yoshimura, 2013). In this study, synthesized core-shell-structured carbon nanofiber (CNF)-titanate nanotubes (TiNT) by alkaline hydrothermal treatment. The CNF core could act as a support, and the $\mathrm{TiO}_{2}$ decorated TiNT shell could act as a photocatalyst. The surface area increase as a result of the alkaline hydrothermal treatment may be responsible for the efficient photocatalytic activity of CNF-TiNTs (Kim et al., 2014; Kong et al., 2014; Guo et al., 2019).

\section{Chemical Vapor Deposition (CVD) on Catalyst Nanoparticles}

This method is often used in the semiconductor industry to obtain high clearing solid materials or thin films. Typically, during CVD, the substrate (catalyst) is placed in the precursor vapor and then the reaction produces the necessary substance. This process is used to obtain clean CNMs by making CNTs and CNFs then removing them from the nanoparticle-catalyst (substrate) surface (Bhat, 2006; Kumar and Ando, 2010; Prasek et al., 2011; Zhang et al., 2013; Bauman et al., 2017).

Nanomaterials can be used with the catalyst particles without separation. This resulting material is a hybrid. Here, catalyst particles act as both a substrate under the growing carbon nanomaterials, and as an arming dopant (Lee et al., 2002; Nessim, 2010). For use in ecology or the medical industry, catalysts must be non-toxic or must decrease the toxicity of carbon nanomaterials (Yu et al., 2011; Cendrowski et al., 2014; Chen J. et al., 2014).

In their publication, Cao et al. (2003) use this method to control the position and growth of CNTs (their length and direction) on the plane. Nanotube bridges connect samples of $\mathrm{SiO}_{2}$ and demonstrate good electrical properties. It is important to note that $\mathrm{SiO}_{2}$ neither coats CNTs nor decreases the conductivity. This method seems simple, inexpensive and controlled. Synthesized nanowires with dielectric shells present a new possibility for the effective and simple creation of highpressure vertical broadband devices (Li et al., 2007).

Growing nanofibers on sphere nanoparticles leads to a significant increase in the fiber surface area. The reaction of growing CNTs decreases fiber strength, but the fiber module significantly increases, with compounds having grown CNTs fibers exhibiting significant improvement (up to 150\%) in apparent shear strength in the transverse direction (Qian et al., 2010). The idea of hybridizing CNTs and $\mathrm{Al}_{2} \mathrm{O}_{3}$ is based on agglomeration prevention of CNTs due to Van der Waals interaction. Epoxide compounds with $\mathrm{CNTs}-\mathrm{Al}_{2} \mathrm{O}_{3}$ demonstrate magnification $>100 \%$ of compressive strength and Young's modulus (Zakaria et al., 2016). The introduction of nanocatalysts by this method is designed to improve the thermal properties of CNMs (Kumar et al., 2008; Ahmad et al., 2009, 2010).

\section{Electrostatic Self-Assembly}

This method is realized due to the interaction of the charged of particles on surface charged substrate, resulting in strong bond formation and uniformed distribution (Fang and Böhringer, 2008; Liu Y. et al., 2009; Olmedo et al., 2011; Choi et al., 2014). One-dimensional nanocomposite colloids are prepared through electrostatic self-assembly of CdTe nanocrystals on both carbon nanotubes (CNTs) and silica coated CNTs. The dense coverage of these linear nanoparticle assemblies minimizes the spacing between the nanocrystals, thereby facilitating efficient electron and energy transfer along the nanotubes (Grzelczak et al., 2006; Bogani et al., 2009; Liu Y. et al., 2009; Downes et al., 2015).

\section{HYBRID MATERIALS FOR ENVIRONMENTAL APPLICATIONS}

Hybrid carbon nanomaterials are used in many areas of our life, such as medicine, material science, and environmental concerns. These are not the only areas, but, due to the main properties of CNMs, the nanosystems would be most effective in the aforementioned fields due to the synergetic effect (Table 1). In the current climatic conditions, the environmental situation is such that there is a rising demand to protect the environment from toxic substances. Pollution, the release of harmful substances into the environment, is one of the results of the human lifestyle. The huge release of copper, mercury and other trace elements has produced a list of complex environmental problems. These materials are likely toxic to all living organisms. Highly sensitive and selective results show that these substances have received considerable attention in the last few years (Ghiasvand et al., 2020). Removal of these compounds is a mandatory step in protecting the environment. This topic has interested many scientists from around the world (Song et al., 2010; Ashrafi et al., 2014; Sareen et al., 2014; Zare et al., 2015).

The important area is removing divalent heavy metal ions $\mathrm{Cu}^{2+}, \mathrm{Zn}^{2+}, \mathrm{Pb}^{2+}, \mathrm{Cd}^{2+}, \mathrm{Co}^{2+}$ from aqueous solutions. Pure CNTs (Tofighy and Mohammadi, 2011) and CNFs (Zheng et al., 2014) can be used as sorption agents. Preference of adsorption onto the oxidized CNT sheets can be ordered as $\mathrm{Pb}^{2+}>\mathrm{Cd}^{2+}>$ $\mathrm{Co}^{2+}>\mathrm{Zn}^{2+}>\mathrm{Cu}^{2+}$ (Tofighy and Mohammadi, 2011). In the research of Asmaly et al. (2015), adsorption capacities increase in a row CNFs, untreated CNTs, CNFs- $\mathrm{Fe}_{2} \mathrm{O}_{3}$. The maximal sorption capacity has a material $\mathrm{CNTs}-\mathrm{Fe}_{2} \mathrm{O}_{3}$. In their research Dr. Bagheri et al. propose a CNTs-magnetic $\mathrm{SiO}_{2}$ compound for finding $\mathrm{Cu}^{2+}$ and $\mathrm{Hg}^{2+}$, detectable even by human eyes ( $\mathrm{Li}$ et al., 2007; Khani et al., 2010; Song et al., 2010; Bagheri et al., 2011; Ganjali et al., 2011). Because of its widespread use in modern society, copper poses serious environmental problems and is potentially toxic to all living organisms. Highly sensitive and selective detection of $\mathrm{Cu}^{2+}$ or $\mathrm{Cu}^{+}$has received much attention in recent years.

The environmental impact of uranium and its associated health effects on humans has recently become a major concernmainly due to the use of weakened uranium in armor-piercing bullets (Konstantinou et al., 2013). Radioactive uranium (VI) is weakened and loaded unto silver hydroxide nanoparticlesMWCNTs, which have been identified as an excellent adsorbent for the removal of $\mathrm{UO}_{2}^{2+}$ ion from aqueous solutions (Zare et al., 2015). In this technique, the application of an ultrasonic wave during the synthesis of these nanomaterials led to properties, such as high surface area; enhanced removal percentage and high adsorption capacity; a high number of active centers; and a large number of vacant, available reactive surface sites in addition to metallic or semi-metallic behavior necessary for removal of 
TABLE 1 | Summary of the efficiency of various hybrid materials.

\begin{tabular}{|c|c|c|c|}
\hline Hybrid material & Toxic substances & Sorption capacity & References \\
\hline CNTs-Sb & $\mathrm{Pb}^{2+}, \mathrm{Cd}^{2+}$ & $37.50 \mathrm{ng} / \mathrm{g}, 0.34 \mu \mathrm{g} / \mathrm{g}$ & (Ashrafi et al., 2014) \\
\hline CNTs-AgOH & $\mathrm{UO}_{2}^{2+}$ & $140 \mathrm{mg} / \mathrm{g}$ & (Zare et al., 2015) \\
\hline CNTs sheets & $\mathrm{Pb}^{2+}, \mathrm{Cd}^{2+}, \mathrm{Co}^{2+}, \mathrm{Zn}^{2+}, \mathrm{Cu}^{2+}$ & $117.65,92.59,85.74,74.63,64.93 \mathrm{mg} / \mathrm{g}$ & $\begin{array}{l}\text { (Tofighy and Mohammadi, } \\
\text { 2011) }\end{array}$ \\
\hline CNTs-Ni & Methylene blue & $312 \mathrm{mg} / \mathrm{g}$ & (Jin et al., 2018) \\
\hline $\mathrm{CNTS}-\mathrm{SiO}_{2} / \mathrm{Al}_{2} \mathrm{O}_{3}$ & $\mathrm{NaCl}$ & $6.5 \mathrm{mg} / \mathrm{g}$ & (Santos et al., 2018) \\
\hline $\mathrm{CNFs}-\mathrm{Fe}_{2} \mathrm{O}_{3}, \mathrm{CNTs}-\mathrm{Fe}_{2} \mathrm{O}_{3}$ & Phenol & $1.684,2.778 \mathrm{mg} / \mathrm{g}$ & (Asmaly et al., 2015) \\
\hline CNTs-Cu-BDC MOFs & Bisphenol A & $164.1 \mathrm{mg} / \mathrm{g}$ & (Ahsan et al., 2019) \\
\hline $\mathrm{BN} / \mathrm{rCNT}$ & S & $43 \mathrm{mg} / \mathrm{g}$ & (Xia et al., 2019) \\
\hline CNF-GnP & Methylene blue, Congo red & 1178.5. and $585.3 \mathrm{mg} / \mathrm{g}$ & (Yu et al., 2020) \\
\hline PHO-CNF & $\mathrm{U}(\mathrm{VI})$ & $1550.0 \mathrm{mg} / \mathrm{g}$ & (Lehtonen et al., 2020) \\
\hline Hybrid material & Dye & Photocatalytic activity & References \\
\hline CNTs- $\mathrm{TiO}_{2}$ & Reactive Black 5 & $90 \% / 15 \min$ & (Hamid et al., 2014) \\
\hline $\mathrm{CNTS}-\mathrm{TiO}_{2}-\mathrm{SiO}_{2}$ & Bisphenol A, carbamazepine & $50 \% / 30 \mathrm{~min}$ & (Czech and Buda, 2015) \\
\hline $\mathrm{CNFs}-\mathrm{Fe}_{3} \mathrm{O}_{4}$ & Methylene blue, Rhodamine B (RhB) & $95 \% / 15 \min$ & $\begin{array}{l}\text { (Ren et al., 2012; Si et al., } \\
\text { 2012) }\end{array}$ \\
\hline $\mathrm{CNFs}_{-} \mathrm{TiO}_{2}-\mathrm{ZnO}$ & Methylene blue & $40 \% / 15 \mathrm{~min}$ & (Pant et al., 2013) \\
\hline CNTs- $\mathrm{PbBiO}{ }_{2} \mathrm{Br}$ & Ciprofloxacin & $50 \% / 30 \mathrm{~min}$ & (Wang B. et al., 2019) \\
\hline $\mathrm{CNTS}_{\mathrm{MoS}} / \mathrm{SnS}_{2}$ & $\mathrm{Cr}(\mathrm{VI})$ & $100 \% / 90 \mathrm{~min}$ & (Dong et al., 2019) \\
\hline CNTs-CoSnS & Rhodamine B & $91.7 \% / 80 \mathrm{~min}$ & (Jeyagopal et al., 2020) \\
\hline CNFs-Cu & Chlortetracycline hydrochloride & $68.2 \% / 60 \mathrm{~min}$ & (Wang H. et al., 2019) \\
\hline
\end{tabular}

various toxic materials (Fasfous and Dawoud, 2012; Sun et al., 2012; Chen et al., 2013; Tan et al., 2015).

Photocatalytic or adsorptive removal of organic pollutants has often been based on the example of phenol, that propagates to other toxic, organic, aromatic poisons (Ren et al., 2012; Si et al., 2012; Asmaly et al., 2015; Tho et al., 2018). Also, it can be methylene blue (Kim et al., 2011; Yu et al., 2011; Saud et al., 2015; Yu et al., 2015; Tho et al., 2018), 4-chlorophenol (Liu H. et al., 2009; Ihsanullah et al., 2015; Zouzelka et al., 2016), Remazol Black Brilliant (Shakouri et al., 2016), visiblelight photocatalytic activity in the degradation of Rhodamine B (RhB) (Shang et al., 2013; Jiang et al., 2015), bisphenol A and carbamazepine (Czech and Buda, 2015), acetaminophen (Czech and Buda, 2015). In the submitted article (Ivnitski et al., 2008) nanocomposite $\mathrm{CNT}-\mathrm{TiO}_{2} / \mathrm{SiO}_{2}$ was synthesized using the solgel method. Up to a $2.2 \mathrm{eV}$ decrease in the bandgap was observed in the resulting material. Composites containing 8 mass \% CNT exhibited maximum photoactivity. This article (Whitsitt and Barron, 2003) illustrates the decreased toxicity of this material. There is no limit to a number of components for a potential hybrid material. For example, $\mathrm{TiO}_{2} / \mathrm{CCNFs}$ (Graphene/carbon composite nanofibers) $\mathrm{TiO}_{2} / \mathrm{ZnO} / \mathrm{CNF}$, CdS/TiO $/$ CNFs, AgAgI- $-\mathrm{TiO}_{2} / \mathrm{CNF}$ in articles (Kim et al., 2012; Pant et al., 2013, 2014; Yu et al., 2015), respectively show multicomponent hybrid materials. The composites showed high adsorption and photocatalytic activity under irradiation due to the synergetic effect between high adsorption ability, good conductivity of CNMs, and extraordinary plasmonic effect of nanoparticles.

\section{FUTURE DIRECTIONS AND CONCLUDING REMARKS}

Today, the scientific community has obtained promising results in the filamentous carbon based hybrid materials area. Hybrid materials are unique in that their properties are not the sum of the properties of the individual components, but their synergy. The hybrid structure provides an additional degree of freedom, which when developing new materials can lead to the emergence of new or improved properties (conductivity, sorption, catalytic, mechanical, optical, and magnetic properties). Currently, the problem of environmental protection remains one of the most urgent in the world. Hybrids based on carbon nanotubes and carbon nanofibers in combination with inorganic (metal oxide) nanoparticles can potentially solve the problems of water and air pollution, and recycling. With them being highly efficient sorbents and photocatalysts, higher productivity can be seen using less material. Therefore, this area of the research has high potential in the development of high-performance materials. Meanwhile, future work toward obtaining the compatibility between carbon nanomaterials and functional nanomaterials is essential to advance the use of these hybrids in electronic, magnetic and environmental applications. Additionally, a better understanding of the key features of forming carbon based hybrids (including by functionalizing the carbon surface) will the development of novel protocols that can generate ideas for more affordable and reliable approaches to the production of advanced hybrid materials. 


\section{AUTHOR CONTRIBUTIONS}

EK, PK, and MS conceptualized the manuscript and completed the text. DA and AN drafted the manuscript.

\section{REFERENCES}

Aazam, E. S. (2014). Visible light photocatalytic degradation of thiophene using $\mathrm{Ag}-\mathrm{TiO}_{2} /$ multi-walled carbon nanotubes nanocomposite. Ceramics Int. 40, 6705-6711. doi: 10.1016/j.ceramint.2013.11.132

Aghabozorg, M. H., Rashidi, A., and Mohammadi, S. (2016). Experimental investigation of heat transfer enhancement of $\mathrm{Fe}_{2} \mathrm{O}_{3}-\mathrm{CNT} /$ water magnetic nanofluids under laminar, transient and turbulent flow inside a horizontal shell and tube heat exchanger. Exp. Thermal Fluid Sci. 72, 182-189. doi: 10.1016/j.expthermflusci.2015.11.011

Ahmad, I., Fay, M., Kennedy, M., and Zhu, Y. Q. (2009). "Interfacial investigations and mechanical properties of carbon nanotube reinforcing $\mathrm{Al}_{2} \mathrm{O}_{3}$ nanocomposites," in ICCM International Conferences on Composite Materials (Nottingham). doi: 10.1016/j.wear.2010.03.009

Ahmad, I., Unwin, M., Cao, H., Chen, H., Zhao, A., Kennedy, A., et al. (2010). Multi-walled carbon nanotubes reinforced $\mathrm{Al}_{2} \mathrm{O}_{3}$ nanocomposites: mechanical properties and interfacial investigations. Compos. Sci. Technol. 70, 1199-1206. doi: 10.1016/j.compscitech.2010.03.007

Ahsan, A., Jabbari, V., Islam, T., Turley, R. S., Dominguez, N., Kim, H., et al. (2019). Sustainable synthesis and remarkable adsorption capacity of $\mathrm{MOF} /$ graphene oxide and MOF/CNT based hybrid nanocomposites for the removal of bisphenol a from water. Sci. Total Environ. 673, 306-317. doi: 10.1016/j.scitotenv.2019.03.219

Aqel, A., Abou El-Nour, K. M. M., Ammarc, R. A. A., and Al-Warthan, A. (2012). Carbon nanotubes, science and technology part (I) structure, synthesis and characterisation. Arab. J. Chem. 5, 1-23. doi: 10.1016/j.arabjc.2010. 08.022

Ashrafi, A. M., Cerovac, S., Mudrić, S., Guzsvány, V., Husáková, L., and Urbanová, I. (2014). Antimony nanoparticle-multiwalled carbon nanotubes composite immobilized at carbon paste electrode for determination of trace heavy metals. Sensors Actuators B Chem. 191, 320-325. doi: 10.1016/j.snb.2013.08.087

Asmaly, H. A., Abussaud, B., Ihsanullah, Saleh, T. A., Gupta, V. K., and Atieh, M. A. (2015). Ferric oxide nanoparticles decorated carbon nanotubes and carbon nanofibers: from synthesis to enhanced removal of phenol. J. Saudi Chem. Soc. 19, 511-520. doi: 10.1016/j.jscs.2015.06.002

Bagheri, H., Ayazi, Z., and Aghakhani, A. (2011). A novel needle trap sorbent based on carbon nanotube-sol-gel for microextraction of polycyclic aromatic hydrocarbons from aquatic media. Anal. Chim. Acta 683, 212-220. doi: 10.1016/j.aca.2010.10.026

Baruah, S., and Dutta, J. (2009). Hydrothermal growth of ZnO nanostructures. Sci. Technol. Adv. Mater. 10:013001. doi: 10.1088/1468-6996/10/1/013001

Bauman, Y., Mishakov, I., Vedyagin, A., Rudnev, A., Plyusnin, P., Shubin, Y., et al. (2017). Promoting effect of $\mathrm{Co}, \mathrm{Cu}, \mathrm{Cr}$ and Fe on activity of Ni-based alloys in catalytic processing of chlorinated hydrocarbons. Topics Catal. 60, 171-177. doi: 10.1007/s11244-016-0729-1

Benad, A., Jürries, F., Vetter, B., Klemmed, B., Hübner, R., Leyens, C., et al. (2018). Mechanical properties of metal oxide aerogels. Chem. Mater. 30, 145-152. doi: 10.1021/acs.chemmater.7b03911

Bergmann, C. P., and Machado, F. M. (2015). "Carbon nanomaterials as adsorbents for environmental and biological applications," in: Carbon Nanostructures, eds C. P. Bergmann and F. M. Machado (Cham: Springer International Publishing). doi: 10.1007/978-3-319-18875-1

Bhat, D. (2006). "Chemical vapor deposition," in Coatings technology: fundamentals, testing, and processing techniques, ed A. A. Tracton (CRC Press). doi: 10.1201/9781420044089.ch36

Bogani, L., Danieli, C., Biavardi, E., Bendiab, N., Barra, A.-L., Dalcanale, E., et al. (2009). Single-molecule-magnet carbon-nanotube hybrids. Angew. Chem. Int. Ed. 48, 746-750. doi: 10.1002/anie.200804967

Bright, W. (2000). Note. Lang. Soc. 29, 155-155. doi: 10.1017/S00474045000 01044

\section{FUNDING}

This work was financially supported by a grant from the Russian Foundation for Basic Research (project No. 18-29-19053_mk).

Byrappa, K., and Adschiri, T. (2007). Hydrothermal technology for nanotechnology. Prog. Crystal Growth Charac. Mater. 53, 117-166. doi: 10.1016/j.pcrysgrow.2007.04.001

Byrappa, K., and Yoshimura, M. (2013). Handbook of Hydrothermal Technology. Waltham, MA: Elsevier. doi: 10.1016/B978-0-12-375090-7.00002-5

Cao, A., Baskaran, R., Frederick, M. J., Turner, K., Ajayan, P. M., and Ramanath, G. (2003). Direction-selective and length-tunable in-plane growth of carbon nanotubes. Adv. Mater. 15, 1105-1109. doi: 10.1002/adma.2003 04738

Cendrowski, K., Jedrzejczak, M., Peruzynska, M., Dybus, A., Drozdzik, M., and Mijowska, E. (2014). Preliminary study towards photoactivity enhancement using a biocompatible titanium dioxide/carbon nanotubes composite. J. Alloys Compd. 605, 173-178. doi: 10.1016/j.jallcom.2014.03.112

Chen, J., Luo, H., Shi, H., Li, G., and An, T. (2014). Anatase $\mathrm{TiO}_{2}$ nanoparticlescarbon nanotubes composite: optimization synthesis and the relationship of photocatalytic degradation activity of acyclovir in water. Appl. Catal. A Gen. 485, 188-195. doi: 10.1016/j.apcata.2014.08.004

Chen, L., Youji, L., Peng, X., Ming, L., and Mengxiong, Z. (2014). Carbon nanotube embedded mesoporous titania pore-hole inorganic hybrid materials with high thermal stability, improved crystallinity and visible-light driven photocatalytic performance. Microporous Mesoporous Mater. 195, 319-329. doi: 10.1016/j.micromeso.2014.04.029

Chen, S., Hong, J., Yang, H., and Yang, J. (2013). Adsorption of uranium (VI) from aqueous solution using a novel graphene oxide-activated carbon felt composite. J. Environ. Radioact. 126, 253-258. doi: 10.1016/j.jenvrad.2013.09.002

Chen, Y.-P., Bashir, S., and Liu, J. (2015). "Carbon capture and storage," in Advanced Nanomaterials and Their Applications in Renewable Energy, eds J. L. Liu, and S. Bashir (Waltham, MA: Elsevier), 329-366. doi: 10.1016/B978-0-12-801528-5.00007-5

Choi, C. H., Chung, M. W., Kwon, H. C., Chung, J. H., and Woo, S. I. (2014) Nitrogen-doped graphene/carbon nanotube self-assembly for efficient oxygen reduction reaction in acid media. Appl. Catal. B: Environ. 144, 760-766. doi: 10.1016/j.apcatb.2013.08.021

Choi, W. S., Yang, H. M., Koo, H. Y., Lee, H.-J., Lee, Y. B., Bae, T. S., et al. (2010). Smart microcapsules encapsulating reconfigurable carbon nanotube cores. $A d v$. Funct. Mater. 20, 820-825. doi: 10.1002/adfm.200901739

Cui, W., Du, F., Zhao, J., Zhang, W., Yang, Y., Xie, X., et al. (2011). Improving thermal conductivity while retaining high electrical resistivity of epoxy composites by incorporating silica-coated multi-walled carbon nanotubes. Carbon N. Y. 49, 495-500. doi: 10.1016/j.carbon.2010.09.047

Czech, B., and Buda, W. (2015). Photocatalytic treatment of pharmaceutical wastewater using new multiwall-carbon nanotubes/ $\mathrm{TiO}_{2} / \mathrm{SiO}_{2}$ nanocomposites. Environ. Res. 137, 176-184. doi: 10.1016/j.envres.2014.12.006

Czech, B., Buda, W., Pasieczna-Patkowska, S., and Oleszczuk, P. (2015). MWCNT$\mathrm{TiO}_{2}-\mathrm{SiO}_{2}$ nanocomposites possessing the photocatalytic activity in UVA and UVC. Appl. Catal. B Environ. 162, 564-572. doi: 10.1016/j.apcatb.2014.07.035

Dai, H. (2002). Carbon nanotubes: opportunities and challenges. Surf. Sci. 500, 218-241. doi: 10.1016/S0039-6028(01)01558-8

Das, R., Abd Hamid, S. B., Ali, M. E., Ismail, A. F., Annuar, M. S. M., and Ramakrishna, S. (2014). Multifunctional carbon nanotubes in water treatment: the present, past and future. Desalination 354, 160-179. doi: 10.1016/j.desal.2014.09.032

Deng, Y., Deng, C., Yang, D., Wang, C., Fu, S., and Zhang, X. (2005). Preparation, characterization and application of magnetic silica nanoparticle functionalized multi-walled carbon nanotubes. Chem. Commun. 44:5548-5550. doi: 10.1039/b511683j

Dillon, F. C., Moghal, J., Koós, A., Lozano, J. G., Miranda, L., Porwal, H., et al. (2015). Ceramic composites from mesoporous silica coated multiwall carbon nanotubes. Microporous Mesoporous Mater. 217, 159-166. doi: 10.1016/j.micromeso.2015.06.024 
Dong, R., Zhong, Y., Chen, D., Li, N., Xu, Q., Li, H., et al. (2019). Morphology-Controlled Fabrication of $\mathrm{CNT}_{\mathrm{MoS}} / \mathrm{SnS}_{2}$ nanotubes for promoting photocatalytic reduction of aqueous $\mathrm{Cr}$ (VI) under visible light. J. Alloys Compd. 784, 282-292. doi: 10.1016/j.jallcom.2019.01.032

Downes, R. D., Hao, A., Park, J. G., Su, Y.-F., Liang, R., Jensen, B. D., et al. (2015). Geometrically constrained self-assembly and crystal packing of flattened and aligned carbon nanotubes. Carbon N. Y. 93, 953-966. doi: 10.1016/j.carbon.2015.06.012

Eder, D. (2010). Carbon nanotube-inorganic hybrids. Chem. Rev. 110, 1348-1385. doi: $10.1021 / \mathrm{cr} 800433 \mathrm{k}$

Fang, J., and Böhringer, K. F. (2008). "Self-assembly," in Comprehensive Microsystems, eds Y. B. Gianchandani, O. Tabata, and H. P. Zappe (Amsterdam: Elsevier), 403-429. doi: 10.1016/B978-044452190-3.00018-5

Fasfous, I. I., and Dawoud., J. N. (2012). Uranium (VI) sorption by multiwalled carbon nanotubes from aqueous solution. Appl. Surf. Sci. 259, 433-440. doi: 10.1016/j.apsusc.2012.07.062

Feng, L., Xie, N., and Zhong, J. (2014). Carbon nanofibers and their composites: a review of synthesizing, properties and applications. Materials (Basel). 7, 3919-3945. doi: 10.3390/ma7053919

Ganjali, M. R., Alizadeh, T., Azimi, F., Larjani,.B., Faridbod, F., and Norouzi,. P. (2011). Bio-mimetic ion imprinted polymer based potentiometric mercury sensor composed of nano-materials. Int. J. Electrochem. Sci. 6, 5200-5208.

Gao, C., Guo, Z., Liu, J.-H., and Huang, X.-J. (2012). The new age of carbon nanotubes: an updated review of functionalized carbon nanotubes in electrochemical sensors. Nanoscale 4, 1948-1963. doi: 10.1039/c2nr11757f

Ge, Y., Zhu, J., Lu, Y., Chen, C., Qiu, Y., and Zhang, X. (2015). the study on structure and electrochemical sodiation of one-dimensional nanocrystalline $\mathrm{TiO}_{2} @ \mathrm{C}$ nanofiber composites. Electrochim. Acta 176, 989-996. doi: 10.1016/j.electacta.2015.07.105

Ghiasvand, A., Yazdankhah, F., and Paull, B. (2020). Heating-, coolingand vacuum-assisted solid-phase microextraction (HCV-SPME) for efficient sampling of environmental pollutants in complex matrices. Chromatographia 83, 531-540. doi: 10.1007/s10337-020-03869-0

Gomathi, A., Vivekchand, S. R. C., Govindaraj, A., and Rao, C. N. R. (2005). Chemically bonded ceramic oxide coatings on carbon nanotubes and inorganic nanowires. Adv. Mater. 17, 2757-2761. doi: 10.1002/adma.200500539

Grzelczak, M., Correa-Duarte, M. A., Salgueiriño-Maceira, V., Giersig, M., Diaz, R., and Liz-Marzán, L. M. (2006). Photoluminescence quenching control in quantum dot-carbon nanotube composite colloids using a silica-shell spacer. Adv. Mater. 18, 415-420. doi: 10.1002/adma.200501523

Guo, H., Jiang, S., Wang, C., Li, S., Feng, J., and Sun, H. (2019). Carbonaceous nanofibers-titanium dioxide nanocomposites: synthesis and use as a platform for removal of dye pollutants. J. Wuhan Univ. Technol. Mater. Sci. Ed. 34, 303-307. doi: 10.1007/s11595-019-2051-9

Hameed, A., Mukhtar, A., Shafiq, U., Qizilbash, M., Khan, M. S., Rashid, T., et al. (2019). Experimental investigation on synthesis, characterization, stability, thermo-physical properties and rheological behavior of MWCNTs-Kapok seed oil based nanofluid. J. Mol. Liq. 277, 812-824. doi: 10.1016/j.molliq.2019.01.012

Hamid, S. B. A., Tan, T. L., Lai, C. W., and Samsudin, E. M. (2014). Multiwalled carbon nanotube/ $\mathrm{TiO}_{2}$ nanocomposite as a highly active photocatalyst for photodegradation of reactive black 5 dye. Chin J. Catal. 35, 2014-2019. doi: 10.1016/S1872-2067(14)60210-2

Hang, B. T., Watanabe, T., Eashira, M., Okada, S., Yamaki, J., Hata, S., et al. (2005). The electrochemical properties of $\mathrm{Fe}_{2} \mathrm{O}_{3}$-loaded carbon electrodes for iron-air battery anodes. J. Power Sources 150, 261-271. doi: 10.1016/j.jpowsour.2005.02.028

Hassan, M. S., Amna, T., Hwang, I. H., and Khil, M.-S. (2013). One-step facile construction of high aspect ratio $\mathrm{Fe}_{3} \mathrm{O}_{4}$ decorated CNFs with distinctive porous morphology: potential multiuse expectations. Colloids Surf. B Biointerfaces 106, 170-175. doi: 10.1016/j.colsurfb.2013.01.040

Huang, J., Liu, Y., and You, T. (2010). Carbon nanofiber based electrochemical biosensors: a review. Anal. Methods 2:202. doi: 10.1039/b9ay00312f

Ihsanullah, Abbas, A., Al-Amer, A. M., Laoui, T., Al-Marri, M. J., Nasser, M. S., et al. (2016). Heavy metal removal from aqueous solution by advanced carbon nanotubes: critical review of adsorption applications. Separation Purif. Technol. 157, 141-161. doi: 10.1016/j.seppur.2015.11.039

Ihsanullah, Asmaly, H. A., Saleh, T. A., Laoui, T., Gupta, V. K., and Atieh, M. A. (2015). Enhanced adsorption of phenols from liquids by aluminum oxide/carbon nanotubes: comprehensive study from synthesis to surface properties. J. Mol. Liq. 206, 176-182. doi: 10.1016/j.molliq.2015.02.028

Iijima, S. (1991). Helical microtubules of graphitic carbon. Nature 354, 56-58. doi: $10.1038 / 354056 \mathrm{a} 0$

Ivnitski, D., Artyushkova, K., Rincón, R. A., Atanassov, P., Luckarift, H. R., and Johnson, G. R. (2008). Entrapment of enzymes and carbon nanotubes in biologically synthesized silica: glucose oxidase-catalyzed direct electron transfer. Small 4, 357-364. doi: 10.1002/smll.200700725

Jeyagopal, R., Chen, Y., Ramadoss, M., Marimuthu, K., Wang, B., Li, W., et al. (2020). A Three-dimensional porous CoSnS@CNT nanoarchitecture as a highly efficient bifunctional catalyst for boosted OER performance and photocatalytic degradation. Nanoscale 12, 3879-3887. doi: 10.1039/C9N R09588H

Jiang, Z., Jiang, D., Yan, Z., Liu, D., Qian, K., and Xie, J. (2015). A New Visible Light Active Multifunctional ternary composite based on $\mathrm{TiO}_{2}-\mathrm{In}_{2} \mathrm{O}_{3}$ nanocrystals heterojunction decorated porous graphitic carbon nitride for photocatalytic treatment of hazardous pollutant and $\mathrm{H}_{2}$ evolution. Appl. Catal. B Environ. 170-171, 195-205. doi: 10.1016/j.apcatb.2015.01.041

Jin, L., Zhao, X., Qian, X., and Dong, M. (2018). Nickel nanoparticles encapsulated in porous carbon and carbon nanotube hybrids from bimetallic metal-organicframeworks for highly efficient adsorption of dyes. J. Colloid Interf. Sci. 509, 245-253. doi: 10.1016/j.jcis.2017.09.002

Khani, H., Rofouei, M. K., Arab, P., Gupta, V. K., and Vafaei, Z. (2010). Multi-walled carbon nanotubes-ionic liquid-carbon paste electrode as a super selectivity sensor: application to potentiometric monitoring of mercury ion (II). J. Hazard. Mater. 183, 402-409. doi: 10.1016/j.jhazmat.2010.07.039

Kim, C. H., Kim, B.-H., and Yang, K. S. (2011). $\mathrm{TiO}_{2}$ nanoparticles loaded on graphene/carbon composite nanofibers by electrospinning for increased photocatalysis. Carbon N. Y. 50, 2472-2481. doi: 10.1016/j.carbon.2012.01.069

Kim, C. H., Kim, B.-H., and Yang, K. S. (2012). Visible light-induced photocatalytic activity of Ag-containing $\mathrm{TiO}_{2} /$ carbon nanofibers composites. Synthetic Metals. 161, 1068-1072. doi: 10.1016/j.synthmet.2011.03.017

Kim, S., Kim, M., Kim, Y. K., Hwang, S.-H., and Lim, S. K. (2014). Coreshell-structured carbon nanofiber-titanate nanotubes with ednhanced photocatalytic activity. Appl. Catal. B Environ. 148-149, 170-176. doi: 10.1016/j.apcatb.2013.10.051

Kiselev, G. O., Kiseleva, A. P., Ilatovskii, D. A., Koshevaya, E. D., Nazarovskaia, D. A., Gets, D. S., et al. (2019). Upconversion metal (Zr, Hf, and Ta) oxide aerogels. Chem. Commun. 55, 8174-8177. doi: 10.1039/C9CC02452B

Klein, K. L., Melechko, A. V., McKnight, T. E., Retterer, S. T., Rack, P. D., Fowlkes, J. D., et al. (2008). Surface characterization and functionalization of carbon nanofibers. J. Appl. Phys. 103:061301. doi: 10.1063/1.2840049

Kong, J., Wei, Y., Zhao, C., Toh, M. Y., Yee, W. A., Zhou, D., et al. (2014). Growth of Rutile $\mathrm{TiO}_{2}$ on the convex surface of nanocylinders: from nanoneedles to nanorods and their electrochemical properties. Nanoscale 6, 4352-4360. doi: $10.1039 / \mathrm{C} 3 \mathrm{NR} 04308 \mathrm{H}$

Konstantinou, M., Demetriou, A., and Pashalidis, I. (2013). Adsorption of hexavalent uranium on dunite. Glob. NEST J. 9, 229-236. doi: 10.30955 /gnj. 000446

Kumar, L., Zhang, T., Du, G., Li, W., Wang, Q., Datye, A., et al. (2008). Thermal properties of CNT-alumina nanocomposites. Compos. Sci. Technol. 68, 2178-2183. doi: 10.1016/j.compscitech.2008.04.001

Kumar, M., and Ando, Y. (2010). Chemical vapor deposition of carbon nanotubes: a review on growth mechanism and mass production. J. Nanosci. Nanotechnol. 10, 3739-3758. doi: 10.1166/jnn.2010.2939

Lee, C. J., Park, J., and Yu, J. A. (2002). Catalyst effect on carbon nanotubes synthesized by thermal chemical vapor deposition. Chem. Phys. Lett. 360, 250-255. doi: 10.1016/S0009-2614(02)00831-X

Lehtonen, J., Hassinen, J., Kumar, A. A., Johansson, L.-S., Mäenpää, R., and Pahimanolis, N. (2020). Phosphorylated cellulose nanofibers exhibit exceptional capacity for uranium capture. Cellulose. doi: 10.1007/s10570-020-02971-8. [Epub ahead of print].

Li, X., Liu, Y., Fu, L., Cao, L., Wei, D., Wang, Y., et al. (2007). Synthesis and device integration of carbon nanotube/silica core-shell nanowires. J. Phys. Chem. C 111, 7661-7665. doi: 10.1021/jp0689417

Li, Z., Gao, B., Chen, G. Z., Mokaya, R., Sotiropoulos, S., and Li Puma, G. (2011). Carbon nanotube/titanium dioxide $\left(\mathrm{CNT} / \mathrm{TiO}_{2}\right)$ coreshell nanocomposites with tailored shell thickness, CNT content and 
photocatalytic/photoelectrocatalytic properties. Appl. Catal. B Environ. 110, 50-57. doi: 10.1016/j.apcatb.2011.08.023

Liang, R.-P., Wang, Z.-X., Zhang, L., and Qiu, J.-D. (2012). A labelfree amperometric immunosensor for alpha-fetoprotein determination based on highly ordered porous multi-walled carbon nanotubes/silica nanoparticles array platform. Sensors Actuators B Chem. 166-167, 569-75. doi: 10.1016/j.snb.2012.03.011

Liu, H., Li, J., Liu, X., and Jiang, S. (2009). A novel multiwalled carbon nanotubes bonded fused-silica fiber for solid phase microextraction-gas chromatographic analysis of phenols in water samples. Talanta 78, 929-935. doi: 10.1016/j.talanta.2008.12.061

Liu, X., Wang, M., Zhang, S., and Pan, B. (2013). Application potential of carbon nanotubes in water treatment: a review. J. Environ. Sci. 25, 1263-1280. doi: 10.1016/S1001-0742(12)60161-2

Liu, Y., Jiang, W., Li, S., and Li, F. (2009). Electrostatic self-assembly of $\mathrm{Fe}_{3} \mathrm{O}_{4}$ nanoparticles on carbon nanotubes. Appl. Surf. Sci. 255, 7999-8002. doi: 10.1016/j.apsusc.2009.05.002

Miller, J. B., and Ko, E. I. (1996). Acidic properties of silica-containing mixed oxide aerogels:preparation and characterization of zirconia-silica and comparison to titania-silica. J. Catal. 159, 58-68. doi: 10.1006/jcat.1996.0064

Mishakov, I., Buyanov, R., Zaikovskii, V., Strel'tsov, I., and Vedyagin, A. (2008). Catalytic synthesis of nanosized feathery carbon structures via the carbide cycle mechanism. Kinetics Catal. 49, 868-872. doi: 10.1134/S00231584080 60116

Navrotskaya, A. G., Krivoshapkina, E. F., Perovskiy, I. A., Bauman, Y. I., Mishakov, I. V., Vedyagin, A. A., et al. (2019). Synthesis and properties of carbon-metal oxide nanomaterials. J. Sol-Gel Sci. Technol. 92, 449-457. doi: 10.1007/s10971-019-04974-9

Nessim, G. D. (2010). Properties, synthesis, and growth mechanisms of carbon nanotubes with special focus on thermal chemical vapor deposition. Nanoscale 2, 1306-1323. doi: 10.1039/b9nr00427k

Olmedo, M., Wang, C., Ryu, K., Zhou, H., Ren, J., Zhan, N., et al. (2011). Carbon nanotube memory by the self-assembly of silicon nanocrystals as charge storage nodes. ACS Nano 5, 7972-7977. doi: 10.1021/nn202377f

Pant, B., Barakat, N. A. M., Pant, H. R., Park, M., Saud, P. S., Kim, J.W., et al. (2014). Synthesis and photocatalytic activities of $\mathrm{CdS} / \mathrm{TiO} 2$ nanoparticles supported on carbon nanofibers for high efficient adsorption and simultaneous decomposition of organic dyes. J. Colloid Interf. Sci. 434, 159-166. doi: 10.1016/j.jcis.2014.07.039

Pant, B., Pant, H. R., Barakat, N. A. M., Park, M., Jeon, K., Choi, Y., et al. (2013). Carbon nanofibers decorated with binary semiconductor $\left(\mathrm{TiO}_{2} / \mathrm{ZnO}\right)$ nanocomposites for the effective removal of organic pollutants and the enhancement of antibacterial activities. Ceramics Int. 39, 7029-7035. doi: 10.1016/j.ceramint.2013.02.041

Paula, A. J., Stéfani, D., Souza Filho, A. G., Kim, Y. A., Endo, M., and Alves, O. L. (2011). Surface chemistry in the process of coating mesoporous $\mathrm{SiO}_{2}$ onto carbon nanotubes driven by the formation of SiOC bonds. Chem. A Eur. J. 17, 3228-3237. doi: 10.1002/chem.201002455

Pirajno, F. (2009). Hydrothermal Processes and Mineral Systems. East Perth: Springer. doi: 10.1007/978-1-4020-8613-7

Postnov, V. N., Rodinkov, O. V., Moskvin, L. N., Novikov, A. G., Bugaichenko, A. S., and Krokhina, O. A. (2016). From carbon nanostructures to highperformance sorbents for chromatographic separation and preconcentration. Russian Chem. Rev. 8, 115-138. doi: 10.1070/RCR4551

Poveda, R. L., and Gupta, N. (2016). Carbon Nanofiber Reinforced Polymer Composites. SpringerBriefs in Materials. Cham: Springer International Publishing.

Prasek, J., Drbohlavova, J., Chomoucka, J., Hubalek, J., Jasek, O., Adam, V., et al. (2011). Methods for carbon nanotubes synthesis-review. J. Mater. Chem. 21:15872. doi: 10.1039/c1jm12254a

Qian, H., Bismarck, A., Greenhalgh, E. S., and Shaffer, M. S. P. (2010). Carbon nanotube grafted silica fibres: characterising the interface at the single fibre level. Compos. Sci. Technol. 70, 393-399. doi: 10.1016/j.compscitech.2009.11.014

Rabti, A., Raouafi, N., and Merkoçi, A. (2016). Bio(Sensing) devices based on ferrocene-functionalized graphene and carbon nanotubes. Carbon N. Y. 108, 481-514. doi: 10.1016/j.carbon.2016.07.043
Rao, G. P., Lu, C., and Su, F. (2007). Sorption of divalent metal ions from aqueous solution by carbon nanotubes: a review. Separation Purif. Technol. 58, 224-231. doi: 10.1016/j.seppur.2006.12.006

Ren, T., Si, Y., Yang, J., Ding, B., Yang, X., Hong, F., et al. (2012). Polyacrylonitrile/polybenzoxazine-based $\quad \mathrm{Fe}_{3} \mathrm{O}_{4} @$ carbon nanofibers: hierarchical porous structure and magnetic adsorption property. J. Mater. Chem. 22, 15919-15927. doi: 10.1039/c2jm33214k

Sahoo, N. G., Rana, S., Cho, J. W., Li, L., and Chan, S. H. (2010). Polymer nanocomposites based on functionalized carbon nanotubes. Prog. Polym. Sci. 35, 837-867. doi: 10.1016/j.progpolymsci.2010.03.002

Santos, C., Lado, J. J., García-Quismondo, E., Rodríguez, I. V., Hospital-Benito, D., Palma, J., et al. (2018). Interconnected metal oxide CNT fibre hybrid networks for current collector-free asymmetric capacitive deionization. J. Mater. Chem. A 6, 10898-10908. doi: 10.1039/C8TA01128A

Sareen, D., Kaur, P., and Singh, K. (2014). Strategies in detection of metal ions using dyes. Coord. Chem. Rev. 265, 125-154. doi: 10.1016/j.ccr.2014.01.015

Sarkar, B., Mandal, S., Tsang, Y. F., Kumar, P., Kim, K.-H., and Ok, Y. S. (2018). Designer carbon nanotubes for contaminant removal in water and wastewater: a critical review. Sci. Total Environ. 612, 561-581. doi: 10.1016/j.scitotenv.2017.08.132

Saud, P. S., Pant, B., Alam, A.-M., Ghouri, Z. K., Park, M., and Kim, H.-Y. (2015). Carbon quantum dots anchored $\mathrm{TiO}_{2}$ nanofibers: effective photocatalyst for waste water treatment. Ceramics Int. 41, 11953-11959. doi: 10.1016/j.ceramint.2015.06.007

Shakouri, A., Heris, S. Z., Etemad, S. G., and Mousavi, S. M. (2016). Photocatalytic activity performance of novel cross-linked PEBAX copolymer nanocomposite on Azo dye degradation. J. Mol. Liq. 216, 273-283. doi: 10.1016/j.molliq.2016.01.008

Shang, M., Wang, W., Sun, S., Gao, E., Zhang, Z., Zhang, L., et al. (2013). The design and realization of a large-area flexible nanofiber-based mat for pollutant degradation: an application in photocatalysis. Nanoscale 5:5036. doi: $10.1039 / \mathrm{c} 3 \mathrm{nr} 00503 \mathrm{~h}$

Si, Y., Ren, T., Li, Y., Ding, B., and Yu, J. (2012). Fabrication of magnetic polybenzoxazine-based carbon nanofibers with $\mathrm{Fe}_{3} \mathrm{O}_{4}$ inclusions with a hierarchical porous structure for water treatment. Carbon N. Y. 50, 5176-5185. doi: 10.1016/j.carbon.2012.06.059

Song, Y., Qu, K., Xu, C., Ren, J., and Qu, X. (2010). Visual and quantitative detection of copper ions using magnetic silica nanoparticles clicked on multiwalled carbon nanotubes. Chem. Commun. 46, 6572-6574. doi: $10.1039 / \mathrm{c} 0 \mathrm{cc} 01593 \mathrm{~h}$

Sun, C., Chen, S., and Li, Z. (2018). Controllable synthesis of $\mathrm{Fe}_{2} \mathrm{O}_{3}$-carbon fiber composites via a facile sol-gel route as anode materials for lithium ion batteries. Appl. Surf. Sci. 427, 476-484. doi: 10.1016/j.apsusc.2017. 08.070

Sun, Y., Yang, S., Sheng, G., Guo, Z., and Wang, X. (2012). The removal of U(VI) from aqueous solution by oxidized multiwalled carbon nanotubes. J. Environ. Radioact. 105, 40-47. doi: 10.1016/j.jenvrad.2011.10.009

Sun, Z., Yuan, H., Liu, Z., Han, B., and Zhang, X. (2005). A highly efficient chemical sensor material for $\mathrm{H}_{2} \mathrm{~S}: \alpha-\mathrm{Fe}_{2} \mathrm{O}_{3}$ nanotubes fabricated using carbon nanotube templates. Adv. Mater. 17, 2993-2997. doi: 10.1002/adma.2005 01562

Tan, L., Liu, Q., Jing, X., Liu, J., Song, D., Hu, S., et al. (2015). Removal of Uranium (VI) ions from aqueous solution by magnetic cobalt ferrite/multiwalled carbon nanotubes composites. Chem. Eng. J. 273, 307-315. doi: 10.1016/j.cej.2015.01.110

Thakur, V. K., and Thakur, M. K. (2016). Chemical Functionalization of Carbon Nanomaterials: Chemistry and Applications. Boca Raton, FL: CRC Press.

Tho, N. H., Thy, T. T. M., Dat, P. T., Minh, V. C., and Sang, N. X. (2018). Physical adsorption and photocatalytic activity of titanium dioxide nanotube and graphene oxide composite. VNU J. Sci. 34:4770. doi: 10.25073/2588-1140/vnunst.4770

Tofighy, M. A., and Mohammadi, T. (2011). Adsorption of divalent heavy metal ions from water using carbon nanotube sheets. J. Hazard. Mater. 185, 140-147. doi: 10.1016/j.jhazmat.2010.09.008

Vashist, A., Ajeet, K., Atul, V., Vidya, S., Ghosal, A., Gupta, Y. K., et al. (2018a). Advances in carbon nanotubes-hydrogel hybrids in nanomedicine for therapeutics. Adv. Healthc. Mater. 7:e1701213. doi: 10.1002/adhm.201701213 
Vashist, A., Kaushik, A., Vashist, A., Sagar, V., Ghosal, A., Gupta, Y. K., et al. (2018b). Study of $\mathrm{MgO}$ transformation into $\mathrm{MgF}_{2}$ in the presence of $\mathrm{CF}_{2} \mathrm{Cl}_{2}$. J. Serbian Chem. Soc. 82, 523-538. doi: 10.2298/JSC161020037V

Wan, Y., Yang, Z., Xiong, G., Guo, R., Liu, Z., and Luo, H. (2015). Anchoring $\mathrm{Fe} 3 \mathrm{O} 4$ nanoparticles on three-dimensional carbon nanofibers toward flexible high-performance anodes for lithium-ion batteries. J. Power Sources 294, 414-419. doi: 10.1016/j.jpowsour.2015.06.057

Wang, B., Liu, G., Ye, B., Ye, Y., Zhu, W., Yin, S., et al. (2019). Novel $\mathrm{CNT} / \mathrm{PbBiO}_{2} \mathrm{Br}$ hybrid materials with enhanced broad spectrum photocatalytic activity toward ciprofloxacin (CIP) degradation. J. Photochem. Photobiol. A: Chem. 382:111901. doi: 10.1016/j.jphotochem.2019.111901

Wang, H., Zhang, J., Yuan, X., Jiang, L., Xia, Q., and Chen, H. (2019). Photocatalytic removal of antibiotics from natural water matrices and swine wastewater via $\mathrm{Cu}(\mathrm{I})$ coordinately polymeric carbon nitride framework. Chem. Eng. J. 392:123638. doi: 10.1016/j.cej.2019.123638

Whitsitt, E. A., and Barron, A. R. (2003). Silica coated single walled carbon nanotubes. Nano Lett. 3, 775-778. doi: 10.1021/nl034186m

Wu, Z., Dong, F., Zhao, W., Wang, H., Liu, Y., and Guan, B. (2009). The fabrication and characterization of novel carbon doped $\mathrm{TiO}_{2}$ nanotubes, nanowires and nanorods with high visible light photocatalytic activity. Nanotechnology 20:235701. doi: 10.1088/0957-4484/20/23/235701

Wu, Z., Gao, S., Chen, L., Jiang, D., Shao, Q., Zhang, B., et al. (2017). Electrically insulated epoxy nanocomposites reinforced with synergistic coreshell $\mathrm{SiO}_{2} @$ MWCNTs and montmorillonite bifillers. Macromol. Chem. Phys. 218:1700357. doi: 10.1002/macp.201700357

Xia, D., Li, H., Huang, P., Mannering, J., Zafar,. U., Baker, D., et al. (2019). Boronnitride/carbon-nanotube hybrid aerogels as multifunctional desulfurisation agents. J. Mater. Chem. A 7, 24027-24037. doi: 10.1039/C9TA06599G

Yan, Y., Miao, J., Yang, Z., Xiao, F.-X., Yang, H. B., Liu, B., et al. (2015). Carbon nanotube catalysts: recent advances in synthesis, characterization and applications. Chem. Soc. Rev. 44, 3295-3346. doi: 10.1039/C4CS00492B

Yang, S., Li, J., Shao, D., Hu, J., and Wang, X. (2009). Adsorption of $\mathrm{Ni}(\mathrm{II})$ on oxidized multi-walled carbon nanotubes: effect of contact time, PH, foreign ions and PAA. J. Hazard. Mater. 166, 109-116. doi: 10.1016/j.jhazmat.2008.11.003

Yoshimura, M., and Byrappa, K. (2008). Hydrothermal processing of materials: past, present and future. J. Mater. Sci. 43, 2085-2103. doi: 10.1007/s10853-007-1853-x

Yu, D., Bai, J., Liang, H., Wang, J., and Li, C. (2015). Fabrication of a novel visiblelight-driven photocatalyst $\mathrm{Ag}-\mathrm{AgI}-\mathrm{TiO}_{2}$ nanoparticles supported on carbon nanofibers. Appl. Surf. Sci. 349, 241-250. doi: 10.1016/j.apsusc.2015.05.019

Yu, W.-W., Zhang, Q.-H., Shi, G.-Y., Li, Y.-G., and Wang, H.-Z. (2011). Preparation of Pt-loaded $\mathrm{TiO}_{2}$ nanotubes/nanocrystals composite photocatalysts and their photocatalytic properties. J. Inorg. Mater. 26, 747-752. doi: 10.3724/SP.J.1077.2011.00747

Yu, Z., Hu, C., Dichiara, A. B., Jiang, W., and Gu, J. (2020). Cellulose nanofibril/carbon nanomaterial hybrid aerogels for adsorption removal of cationic and anionic organic dyes. Nanomaterials 10:169. doi: 10.3390/nano10010169

Zakaria, M. R., Akil, H. M., Abdul Kudus, M. H., and Othman, M. B. H. (2016). Compressive properties and thermal stability of hybrid carbon nanotube-alumina filled epoxy nanocomposites. Compos. B Eng. 91, 235-242. doi: 10.1016/j.compositesb.2016.01.013

Zare, F., Ghaedi, M., Daneshfar, A., Agarwal, S., Tyagi, I., Saleh, T. A., et al. (2015). Efficient removal of radioactive uranium from solvent phase using $\mathrm{AgOH}-$ MWCNTs nanoparticles: kinetic and thermodynamic study. Chem. Eng. J. 273, 296-306. doi: 10.1016/j.cej.2015.03.002

Zawisza, B., Skorek, R., Stankiewicz, G., and Sitko, R. (2012). Carbon nanotubes as a solid sorbent for the preconcentration of $\mathrm{Cr}, \mathrm{Mn}, \mathrm{Fe}, \mathrm{Co}, \mathrm{Ni}, \mathrm{Cu}, \mathrm{Zn}$ and $\mathrm{Pb}$ prior to wavelength-dispersive X-ray fluorescence spectrometry. Talanta 99 , 918-923. doi: 10.1016/j.talanta.2012.07.059

Zaytseva, O., and Neumann, G. (2016). Carbon nanomaterials: production, impact on plant development, agricultural and environmental applications. Chem. Biol. Technol. Agric. 3:17. doi: 10.1186/s40538-016-0070-8

Zeng, S., Baillargeat, D., Ho, H.-P., and Yong, K.-T. (2014). Nanomaterials enhanced surface plasmon resonance for biological and chemical sensing applications. Chem. Soc. Rev. 43, 3426-3452. doi: 10.1039/c3cs60479a

Zhang, Y., Zhang, L., and Zhou, C. (2013). Review of chemical vapor deposition of graphene and related applications. Acc. Chem. Res. 46, 2329-2339. doi: 10.1021/ar300203n

Zhao, X., He, X. D., Sun, Y., and Wang, L. D. (2011). Carbon nanotubes doped $\mathrm{SiO}_{2} / \mathrm{SiO}_{2}$-PbO double layer high emissivity coating. Mater. Lett. 65, 2592-2594. doi: 10.1016/j.matlet.2011. 06.030

Zheng, Q., Cai, Z., and Gong, S. (2014). Green synthesis of polyvinyl alcohol (PVA)-cellulose nanofibril (CNF) hybrid aerogels and their use as superabsorbents. J. Mater. Chem. A 2, 3110-3118. doi: 10.1039/C3TA1 $4642 \mathrm{~A}$

Zouzelka, R., Kusumawati, Y., Remzova, M., Rathousky, J., and Pauporté, T. (2016). Photocatalytic activity of porous multiwalled carbon nanotube- $\mathrm{TiO}_{2}$ composite layers for pollutant degradation. J. Hazard. Mater. 317, 52-59. doi: 10.1016/j.jhazmat.2016.05.056

Conflict of Interest: The authors declare that the research was conducted in the absence of any commercial or financial relationships that could be construed as a potential conflict of interest.

Copyright (C) 2020 Navrotskaya, Aleksandrova, Krivoshapkina, Sillanpää and Krivoshapkin. This is an open-access article distributed under the terms of the Creative Commons Attribution License (CC BY). The use, distribution or reproduction in other forums is permitted, provided the original author(s) and the copyright owner(s) are credited and that the original publication in this journal is cited, in accordance with accepted academic practice. No use, distribution or reproduction is permitted which does not comply with these terms. 